\section{LA CIENCIA-FILOSOFÍA EN EDUARDO NICOL}

\author{
Juliana González Valenzuela \\ Profesora Emérita \\ Facultad de Filosofía y Letras \\ Universidad Nacional Autónoma de México \\ Circuito escolar S/N. Ciudad Universitaria, 04510 México DF \\ julgv@msn.com
}

\begin{abstract}
In 2007 is commemorated the centenary of Eduardo Nicol, one of the philosophers of Spanish language more outstanding of last decades. With his renoved and reformer vision of the sciencephilosophy, as this one was originally expressed by the Greeks, Nicol confronted the radical crisis that beat to the thought, understood as a free vocation, under the pressure of the modern utilitarism and his current culmination in the imperalism of the technocracy.
\end{abstract}

KEY WORDS: Science-philosophy, true, historicity, simbolic reason, technocracy.

La filosofía que nació en Grecia, nació como episteme o ciencia y, a su vez, la ciencia surgió como filosofía. Se originó de hecho, una misma actividad humana, cuya novedad se centraba en la posibilidad -dice Heráclito - de "hablar de las cosas como son, según su naturaleza"; propósito que sólo podría alcanzarse, sobre la base de una actitud fundamental, del sujeto ante la realidad. Actitud que consiste, para el efesio, en un "estar despiertos" ante "un mundo común" y en un "hablar y actuar como los que comprenden la naturaleza de las cosas". Que se cifra para Platón, en un estado de asombro (thauma) ante lo que es;

\section{THE SCIENCE-PHILOSOPHY IN EDUARDO NICOL}

RESUMEN: En 2007 se conmemora el centenario de Eduardo Nicol, uno de los filósofos de lengua española más sobresalientes de las últimas décadas. Con su renovada y reformadora visión de la ciencia-filosofía, tal y como ésta fue originariamente expresada por los griegos, Nicol afrontó la crisis radical por la que atraviesa el pensar, entendido como una vocación libre, bajo la presión del utilitarismo moderno y su culminación actual en el imperalismo de la tecnocracia.

PALABRAS CLAVE: Ciencia-filosofia, verdad, historicidad, razón simbólica, tecnocracia.

Agradezco a los organizadores de esta Quincena "Pensar en español", por brindarme la oportunidad de participar en este evento conmemorando el Centenario del nacimiento de $m i$

maestro Eduardo Nicol.

En virtud de este "2007 año de la Ciencia", aludiré aquí, muy sucinta y esquemáticamente, a unas cuantas ideas sobre un tema toral en la obra de Nicol: el de la unidad intrínseca de "ciencia" y "filosofia"; tema que, en efecto, recorre centralmente el pensamiento del filósofo hispano-mexicano, radicado en México de

1939 a su muerte en 1999.

en una esencial philía por la sophía, o amor por el conocimiento, en tanto que amor por el ser; $y$, en definitiva, en una expresión suprema de la condición erótica del hombre, plena y carente a la vez. Actitud que consiste, en fin, para Aristóteles, en una disposición de theoría, de ver y conocer, no motivada por otra cosa que por el impulso radical de conocimiento, implantado en la naturaleza humana. Si acaso Aristóteles -como se sabe- hizo una primera distinción entre filosofía o "ciencia primera" (después llamada metafísica) y filosofías o ciencias segundas (las particulares). Pero una y otras conservaron su común origen y su 
común definición y, en todos los casos, la ciencia como tal se concibió como theoría.

Y sabemos, asimismo, que en esta intrínseca unión se mantuvieron ciencia y filosofía hasta tiempos no muy lejanos, y en figuras tan emblemáticas como Newton o Einstein. Pero también es cierto que es justamente esta unidad la que habrá de irse disolviendo progresivamente en el curso de la modernidad, al mismo tiempo que se gestará un nuevo maridaje, ahora entre la ciencia y la tecnología, con la consecuente separación y hasta oposición entre ciencia y filosofía, entre ciencias y Humanidades, pensadas incluso como manifestaciones de "dos culturas". Este proceso, a su vez, coincide con el éxito avasallador de la llamada "tecnociencia" y es correlativo, tanto a un creciente menosprecio por las actividades que carecen de aplicación utilitaria, como a la advertida posibilidad del final de la filosofía, proclamado por varios pensadores.

La cuestión del "porvenir de la filosofía" - de acuerdo con Nicol-conduce en dirección de una vuelta a ese primer comienzo, a un empezar de nuevo; o más precisamente, lleva a lo que él llama la literal re-forma de la filosofía. Esto es, a la recuperación de la forma originaria, del eidos o esencia propia de la filosofía-ciencia, como se originó en Grecia. Por esto, aquello que asegure un nuevo porvenir ha de consistir en la re-avivación de las experiencias primigenias que justamente dieron lugar a su nacimiento o génesis. De ahí que estos orígenes de la ciencia-filosofía, así como sus primeras grandes instauraciones, estén siempre vigentes en la obra de Eduardo Nicol. Puede decirse que, en realidad, los griegos discurren en sus páginas como verdaderos contemporáneos. Heráclito y Platón, en particular, constituyen las dos grandes fuentes en que su filosofía se nutre e inspira, tanto para la re-forma, como para lo que Nicol propone como la re-evolución en la filosofía.

Pierde futuro - dice- todo presente que niega el pasado.

Aquellas que Kant Ilamó "condiciones de posibilidad del conocimiento científico" no son, para Eduardo Nicol, sólo condiciones epistemológicas, ontológicas, metodológicas, sino también, condiciones antropológicas, éticas -tal y como las hicieron patentes los filósofos griegos.
Se trata, en efecto, para Nicol, de recobrar el fundamento vital de la ciencia filosofía cifrado en esa actitud básica o disposición del sujeto humano ante la realidad, que es un "modo de ser" o "estar", de relacionarse con lo que es, con la sola intención de saber "qué es" y "cómo es", y no "para qué sirve"; se trata en suma del ethos de la ciencia.

Tanto la ciencia como la filosofía buscan ser reconocidas por Nicol en aquello que, en definitiva, las unifica, que es precisamente la común actitud humana de literal philía, atracción o amor por la verdad, de vocación por la verdad, como condición de posibilidad de acceder a ésta.

\section{La episteme es philosophía}

En su rigor más puro, el pensamiento racional es una philía.

Ésta es la disposición básica que, en efecto, depende del sujeto del conocimiento; pero no del sujeto puramente racional, sino integral, completo, asumido en sus raíces vitales o vocacionales.

La alétheia es lo contrario del letargos: la verdad es un estado alerta. Representa la vigilia o vigilancia, por contraste con el adormecimiento; el cuidado como algo contrario al descuido [...] La actividad científica tiene como fundamento vital la vocación de la vigilia - dice Nicol con claras resonancias heracliteanas.

Y la actitud de vigilia cognoscitiva consiste en, lo que los griegos formularon como ver las cosas "en sí y por sí mismas" y no como son "para nosotros" o desde los propios intereses subjetivistas, que empañan la visión objetiva. El des-interés, entonces, es el condicionante de la objetividad científica, y corresponde al sustrato ético-existencial del saber de theoría, del saber que anhela ver y conocer. En este sentido, coinciden verdad y desinterés; verdad y philía.

El "en sí y por sí" no significa entonces otra cosa que el hecho de atender a las realidades en ellas y por ellas mismas sin precondicionarlas a nuestro interés, a nuestra necesidad o a nuestro afán de utilizarlas.

[...] La ciencia es el compromiso vocacional, libremente elegido, de vivir diciendo cómo son las cosas en sí mismas. 
Hablar de ciencia "pura" es, en este sentido, hablar de ciencia teorética, esencialmente cognoscitiva, abocada a la búsqueda de la verdad y no de la utilidad.

La razón pura no es, primordialmente la purificación de lo empírico, sino la purificación de lo utilitario.

Pero lo más revelador y decisivo de la teoría nicoliana de la verdad -y a mi juicio una de las aportaciones más significativas de su filosofía-, es su tesis fundamental de la significación triádica - valga decir- de la verdad. Triádica porque consiste en reconocer que el sujeto de la verdad no existe como tal, sino como literal inter-subjetividad, de tal modo que son tres estructuralmente y no dos, los componentes del acto cognoscitivo. $Y$ esto significa que la objetividad, en que la verdad consiste, se haga posible en y por el lenguaje humano. La comunicación intersubjetiva funda la verdad. La visión y el lenguaje, el "ojo" y la "palabra", son - por así decirlo - los "órganos" de la objetividad. Nicol lo expresa de esta forma:

La verdad está en la palabra.

La verdad es objetiva porque es intersubjetiva.

La presencia del interlocutor, siquiera potencial, está inserta necesariamente en el instrumento mismo del pensamiento, que es el símbolo lógico [...] La comunicabilidad del símbolo es intrínseca: la razón es simbólica.

El logos intersubjetivo, es el que "produce" en el nivel científico la referencia a lo real, pero también lo hace en el nivel más fundamental que es el pre científico -donde incluso Nicol encuentra las evidencias metafísicas primeras.

Señaladamente, en el Logos de Heráclito, Eduardo Nicol encontrará un venero primordial para la comprensión de la estructura del conocimiento. Lo decisivo para el autor de Los principios de la ciencia es que el Logos heracliteano tiene tres significados esencialmente conexos: es razón humana, es también palabra o lenguaje, y es asimismo ley o racionalidad inherente a lo real. El saber de verdad es, efectivamente, un modo de razonar y al mismo tiempo de dia-logar o hablar acerca del Logos objetivo, del Gnomon del mundo que -dice el efesio- "lo gobierna todo a través de todo". Esta interdependencia de las tres modalidades del Logos es axial en la metafísica nicoliana.
Y también aquí es Platón el que nutre esta metafísica, particularmente el mito de Aristófanes del Simposio, el cual estaría revelando la índole ontológica, constitutiva, de la comunicación interhumana. La frase platónica que Nicol adopta como epígrafe de su Metafísica de la expresión, "El hombre es símbolo del hombre" remite al hecho fundamental de que lo originario y constitutivo es la afinidad interhumana, la semejanza y complementariedad ("simbolicidad"), inherentes al ser mismo del hombre; pone de manifiesto, en suma, el vínculo intrínseco, la unidad o igualdad primigenia, que se halla en el fondo de la naturaleza humana, más originaria que la alteridad y la separación.

[...] el otro no es un ser ajeno, en el sentido de ontológicamente extraño al propio: con dos partes disímiles no puede recomponerse una unidad. El otro es un ser el que llamamos prójimo, o semejante, porque su ser no es tan ajeno que no pueda apropiarse: tiene constitutivamente la disposición de ser parte del ser propio.

Pero además, la razón es simbólica no solamente por ser dialógica y porque el diálogo se funda en la simbolicidad o complementariedad ontológica interhumana, sino por el hecho evidente de que el logos re-presenta simbólicamente la realidad. Todo lenguaje es símbolo, desde la palabra básica hasta el lenguaje de la ciencia o la filosofía, incluso de la lógica formal, pasando por los símbolos míticos y religiosos. Simbólico sería, en realidad, el infinito universo de las creaciones culturales: arte, ciencia, religión, moralidad, verdadero mundo del hombre.

El ser humano es "animal simbólico" como lo definió Cassirer -con quien Nicol tiene significativa cercanía-, y la simbolicidad se da en las dos direcciones: como puente de unión entre los semejantes, y como puente de unión entre éstos y lo diferente, lo otro, que es la realidad. Pues en efecto:

\section{El símbolo representa algo que no es simbólico}

Dentro de esta evidencia se encierra el enigma esencial que conlleva la función simbólica, esa asombrosa posibilidad de que la realidad objetiva, no simbólica, sea "re-presentada" simbólicamente. ¿Es que los dos reinos del ser, lenguaje y realidad, símbolo y ser, no son absolutamente extraños entre sí? ¿Cómo se explica la "traducción"-por Ilamarla de 
algún modo- de lo que es material a lo que es símbolo o "significado"? En un sentido más general, Nicol resaltará como insuperable misterio la literal metamorfosis por la cual la materia, sin dejar de ser materia, se hace logos, lenguaje, símbolo. Pues, como él asevera:

[...] con el hombre, la materia se trasciende. De la materia nace el logos [...] El logos no tiene peso ni volumen, densidad o temperatura. La materia no tiene historia. Pero de la materia se hizo la historia. Ni la mito-logía ni la onto-logía pueden resolver el tremendo misterio de tal metamorfosis [...]

El misterio se refiere, en efecto, al hecho metafísico de que exista comunidad ontológica entre los dos órdenes diferentes del ser: la materia universal y el logos. Y éste sería el prodigio último del lenguaje y de la ciencia: la re-unión simbólica de los seres humanos con aquello que no es simbólico:

Aquello de que hablamos es "lo otro". No cabe duda de que se trata de lo otro; pero también es cierto que nosotros formamos parte de lo otro. Inmerso en el orden universal e integral del Ser, no hay "otro" para el ser que habla. Es mismidad en la alteridad.

Se revela, en esencia, la pertenencia del hombre y su logos a la materia universal, la cual, a su vez, se reconoce a sí misma en la dimensión simbólica, que emerge de sí.

Podría decirse, que así como por medio de esa prodigiosa creación suya, que es el cerebro humano, la vida llega a hacerse consciente de sí misma y del todo, así también la realidad que "no habla" se reconoce a sí misma en el lenguaje de los hombres, o en términos de la metafísica nicoliana:

Es la palabra el nexo de comunidad ontológica entre los dos órdenes del ser.

En el hombre, el ser se hace logos, el logos se hace ser. Con el logos, el ser habla de sí mismo.

O como lo expresó también Spinoza:

En nosotros, el Universo se piensa, se conoce y se ama a sí mismo
El ethos coincide con la libertad, es de hecho la "segunda naturaleza" por la cual la acción humana se proyecta más allá de la satisfacción de las necesidades de la vida biológica y la mera sobrevivencia; literal sobre-naturaleza que se eleva, sin ruptura, sobre la naturaleza "primera", regida por el orden de la necesidad. "Sobre "ella, y no "sin" ni "contra" -insiste Nicol.

No hay "segunda" naturaleza que rompa con la "primera", así como no hay propiamente naturaleza exclusivamente biológica o instintiva para el hombre, al menos desde el surgimiento del homo sapiens, o sea del hombre histórico. No hay cultura sin natura y, al mismo tiempo, la cultura, el mundo humano simbólico, es inequívocamente irreductible. La continuidad con la naturaleza básica no impide que se produzca el salto cualitativo, por el cual -por paradójico y misterioso que resulte-, emerge desde la naturaleza, sin rompimiento, la dimensión de la libertad.

Y precisamente ciencia y filosofía son manifestación suprema de la condición libre del hombre. Forman parte, de hecho, de las que Eduardo Nicol concibe como vocaciones libres.

Son vocaciones libres porque liberan al hombre del sometimiento al orden de lo meramente necesario, y sobre todo porque se ejercen por otros móviles e intereses, más allá de la acción destinada a los fines de la subsistencia o de la utilidad. Libres porque lo liberan de la mano o manipulación del dominio utilitarista, haciendo posible la posesión y la transformación simbólicas del mundo, al tornarlo inteligible en la comunicación racional. Son vocaciones libres, en fin, porque conllevan, es cierto, el cambio radical de actitud, por el cual el ser humano se relaciona de otro modo con el mundo y se proyecta hacia otros horizontes existenciales; porque ejerce así, las actividades intrínsecamente "des-interesadas", in-necesarias e in-útiles, como habrá de definirlas Nicol. Pues, ciertamente, la poesía no es necesaria, el arte no es necesario, la astronomía básica no es necesaria, la filosofía no es necesaria ni lo es, con ella, la ciencia de philía, la ciencia cuyo fin esencial es el conocimiento. Las vocaciones libres "no sirven", no tienen utilidad práctica. Diriamos que son un dispendio de acción, de creatividad, de inteligencia, de emoción, de imaginación, que no reditúan en cosas, ni en servicios, ni en productos, ni bienes materiales, ni beneficio económico. Expresan el dispendio o "lujo" de toda philía, de todo amor. 
Y sin embargo, "También la libertad es una necesidad" -dice expresamente Nicol.

Desde luego, la acción utilitaria, la invención tecnológica (desde las herramientas del homo faber hasta la monumental y sofisticada construcción de la tecnociencia, con todos sus prodigios), son productos históricos y por consiguiente obra de la humana libertad $-y$ así lo reconoce Nicol-. Pero tales productos representan un grado y una modalidad de libertad, anclada en gran parte a la necesidad de ser útil y satisfacer las exigencias materiales. Y en la tecnología actual -cabe añadir - anclada a la satisfacción de las inconmensurables necesidades artificiales, creadas por la propia tecnología.

A diferencia de esto, las vocaciones innecesarias expresan la libertad por antonomasia.

Y la ciencia en particular, es libertad en tanto que también es póiesis: libertad creadora y no mero reflejo pasivo de la realidad, como se destaca ampliamente en Los Principios de la ciencia. Aunque también aquí se insiste en que la libre creación científica no implica mera invención arbitraria y ficticia, carente de referencia a lo real -como incluso algunos científicos han sostenido, poniendo en crisis la posibilidad misma de la verdad-. No hay "brecha epistemológica" entre las leyes "poéticas" de la ciencia y la realidad.

El problema hace aflorar el supuesto, si no es que el atávico prejuicio -a los ojos de Nicol- de la oposición y exclusión entre historicidad y verdad, otro de los temas capitales de su filosofía -al que aquí sólo podemos aludir-. El meollo está en que -dentro de la conceptuación de Nicol- la historicidad corresponde a la comunidad intersubjetiva, al diá-logo temporal, base de la objetividad misma. La razón histórica es la razón simbólica. La ciencia no alcanza, ni alcanzará, verdades absolutas. Toda verdad científica y filosófica es relativa, hipotética, perfectible, pero no por ello deja de contener conocimientos fundados, racionalmente edificados. Pues toda verdad -insiste Nicol- es expresión de su tiempo y de su mundo sin que o carezca por eso de significación, de referencia verdadera a lo real.

[...] es la intersubjetividad inherente a toda función simbólica la que garantiza la objetividad [...]
Todo lo que significa expresa, todo lo que expresa significa [...]

La naturaleza humana es naturaleza histórica. $Y$ este hecho cardinal, que es el fundamento de la concepción nicoliana del ser del hombre, significa que éste no es "esencia" inmutable, fuera del tiempo y el espacio; y significa asimismo que tal naturaleza no pueda entenderse como algo dado, uniforme y acabado, sino como "adquisición y retención de lo humano" -en palabras de Nicol-. Lo cual remite al carácter ontológico, antes que fáctico 0 existencial, de la libertad.

El ser no me es dado con la limitación final de lo que está completo, sino con la limitación inicial de lo que está dispuesto para ser, y que no es todavía lo que habrá de ser [...] Lo inconcluso del ser es lo que le da fuerza impulsiva.

Libertad y humanidad son la misma cosa.

No hay "esencia" idéntica e intemporal, pero habria, por así decirlo, una especie de "esencialización" histórica que concordaría de algún modo con lo que Eduardo Nicol concibe en términos de "Idea del hombre". No existe una sola Idea, o "forma esencial" de ser hombre. Cada Idea es una modalidad histórica y a la vez ontológica en que e hombre va definiendo su ser en el tiempo, va realizando, de manera única y diversa una naturaleza originariamente potencial. Las Ideas del hombre son diversas en las culturas y en el tiempo. Pero en cada tradición cultural se va dando un proceso constituyente del propio ser, un modo compartido -cambiante y a la vez persistente-de realizar las capacidades más propiamente humanas del hombre. $Y$ justamente para la tradición occidental la ciencia-filosofía sería una expresión cimera de dicha humanidad.

Es su condición inconclusa, por lo demás, lo que explica que el humano sea un ser "vocacional" -como lo define Nicol-: un ser que está "llamado a ser", a realizar su propia la "actualización" de sus capacidades distintivas, entre las que destaca el conocimiento Humanidad es en este sentido "humanización". Y el anhelo de la verdad, en filosofía o en ciencia, es fuente primordial de las actividades que humanizan y satisfacen el "necesario" anhelo de ser.

Es así como puede entenderse la aparente paradoja de que la "inutilidad" de las vocaciones libres, su esencial 
desinterés pragmático, en especial de la ciencia filosofía, correspondan a otro orden de "utilidad" y de "interés" e incluso de "necesidad". El impulso de libertad cognoscitiva no es algo extra natural, mero lujo prescindible, sino que está implantado en la naturaleza humana, con carácter también de "necesidad". Ciencia pura y filosofía son entonces útiles, paradójicamente, por su inutilidad; ellas "sirven" porque "no sirven", son necesarias, porque no lo son. El servicio, el beneficio que ellas prestan corresponde al despliegue de lo propiamente humano, precisamente en la comunicación y en la vinculación libre y desinteresada, con la realidad, la externa y la propia.

"Conocer para ser", dijo Platón.

Toda ventaja en el entender, lo es en el ser, dijo a su vez Gracián FH24 -y asi lo recuerda Nicol.

De esto se desprende que, al igual que las otras vocaciones libres, la filosofía y las ciencias "puras" o básicas tengan un valor social. Son de hecho un bien público, tan digno de procurarse en su propia significación, como los bienes económicos, naturales y materiales, en la suya. La razón teórica o simbólica que manifiestamente no produce cosas materiales, no domina ni manipula la naturaleza, genera en cambio, conocimientos, verdades, sabiduría, entendimiento del mundo, del universo y del hombre mismo; esclarece el sentido de la vida. Su producción mayor es, ciertamente, de indole social, comunitaria, ética, formativa, humanista; su producción mayor es vital, pues como lo expresa Nicol.

La razón no necesita ser útil para ser vital.

Producir un pensamiento libre, o mejor dicho, producir un hombre liberado por el pensamiento: éste es el ofrecimiento de la filosofía [y la ciencia] a la comunidad.

Pero entonces, no se trata del conocimiento por el conocimiento, o del saber por el saber, como ve Nicol. Es el saber para la libertad y la posesión de un mundo común. No existe la ciencia por la ciencia. Ella nace de un interés radical y tiene una repercusión práctica sustancial, que no es su aplicación tecnológica, sino aquélla eminentemente ética $y$, más precisamente, ético-ontológica. Para esto sirve la ciencia de philía en que piensa Eduardo Nicol.

[...] el saber no es un fin, es un medio. Para decirlo con exactitud, es un medio de vida. De qué vida se trata: ésta es toda la cuestión. La vida cualificada por el desinterés es la que busca libertad en una victoria sobre la condición natural del hombre [...] una vida que excluye lo desinteresado es una vida que se mutila a sí misma.

Y más especificamente; la philía por la verdad produce en el mundo algo determinante a los ojos de Nicol: trae consigo lo que él llama el régimen de la verdad, como un hecho que irradia en todas direcciones incorporándose a la vida humana desde el surgimiento de la episteme.

La verdad de este régimen no es una verdad, ésta o aquélla, ni un tesoro de muchas verdades reunidas [...] es, inclusive, algo más que una teoría verdadera, adoptada por la mayoría. La base no está, pues, en las verdades conocidas, en un saber logrado y acaudalado. El régimen de la verdad se encuentra sólo en la disposición a basar la vida en la verdad, y no en otra cosa.

Por siglos han coexistido equilibradamente en la tradición occidental, las actividades utilitarias y pragmáticas, las tecnologías en general, junto con las vocaciones libres. Pero efectivamente, es ese equilibrio el que se ha ido rompiendo, originando en el mundo moderno una perturbadora desproporción. Fue triunfando día a día el proyecto moderno de ciencia anunciado por Bacon, que se condensa en su idea de "conocer es dominar".

Se fue desvaneciendo, así, la conciencia del ethos vocacional el cual todavía Spinoza, por ejemplo, quiso recuperar hablando del conocimiento filosófico o científico como "vinculación por amor", como "unión del alma pensante con la naturaleza entera" y como una forma no pragmática de "philanthropía" de amor por el perfeccionamiento del hombre y la instauración de una vida nueva, esencialmente comunitaria Pero triunfó evidentemente en la modernidad la idea baconiana de la ciencia de dominio, y no la spinoziana de vinculación y unión.

Sobrevino, entonces, cada vez de forma más extendida e intensa, el imperialismo de la tecnología, la substitución de la verdad por la utilidad -o al menos, el uso de la verdad para la utilidad-. Avance que irá progresivamente enrareciendo el espacio de las vocaciones inútiles.

Y así va quedando reducida, cada vez más, la existencia humana a un sistema de quehaceres urgentes, sin posibilidad de liberarse de la prisa y la necesidad. 
El problema no será la tecnología sino la literal tecno-cracia. La invasión del reino de la utilidad y la eficacia, como observa Nicol. El éxito avasallador e imparable, y cada vez más incontrolable, de la civilización tecnológica; éxito descomunal debido precisamente, a la ventajosa amalgama de ciencia y tecnología: de la tecnociencia.

Nicol pondrá singular atención en el carácter uniformado del mundo tecnificado, del mundo que atenta contra la diversidad de la cultura y de lo humano en cuanto tal. Libertad es diversidad e individualidad. En este sentido, es al símbolo mítico de Proteo, hoy en agonía, al que acude Eduardo Nicol para mostrar la amenaza de muerte que conlleva la pérdida de la diversidad humana. El hombre es Proteo, en tanto que éste simboliza el ser que tiene la capacidad de cambiar de forma: lo diametralmente opuesto a la uniformidad o la "uniformación" de la vida. El mundo meramente utilitario y pragmático es el mundo homogenizado y mecanizado en que agoniza Proteo $y$, con él, la capacidad humana de cambiar, de crear modos diferentes de existencia.

Cultura y variedad serían una misma cosa [...]

Hay cultura cuando hay culturas.

Este régimen de la eficacia y predominio de la utilidad configura en cambio la cultura de la violencia, que en los análisis de Nicol, coincide con esa filtración en la sociedad actual del significado meramente instrumentalista y "eficientista" de la vida, caracterizado ante todo por su ubicuidad. 0 en sus palabras:

Cuando [...] la eficacia se adopta como la razón suprema.

El avance imperialista de la tecnología (y con él, la consolidación de la sociedad globalizada y mercantilizada), va desplazando, indudablemente, las vocaciones libres, desvalorizándolas y olvidando su significación. En este sentido, podría añadirse que nos amenaza, junto con la bien llamada "Sociedad de los poetas muertos", la sociedad de "los filósofos muertos", de "los científicos muertos" y del "humanismo muerto", por supuesto.

Y no obstante, tampoco la tecno-cracia como tal, sino sus consecuencias, parecen ser la causa principal de la amenaza del fin de la filosofía y de las vocaciones libres -según lo que advierte Nicol, interpretando los signos del porvenir que están ya presentes en la situación actual.

La amenaza del fin de las vocaciones libres proviene en realidad del precio que ha tenido que pagar la tecno-ciencia por su evolución exitosa y su descomunal desarrollo. 0 sea, proviene del daño ecológico y social al Oikos, a la Casa. Particularmente Nicol pone el acento en los hechos, por todos advertidos, de la explosión demográfica, así como del agotamiento progresivo e irreversible de los recursos naturales, y los deplorables e incuantificables estragos infringidos al planeta. Subraya asimismo el consecuente y exponencial crecimiento del reino de la escasez. La escasez que amenaza el futuro -aunque ya desde ahora comienza a aparecer- anunciándose como escasez para todo el planeta, animales humanos y no humanos. Pues

Cuanto más aumentan los recursos técnicos, más disminuyen proporcionalmente los naturales.

Y decir escasez es decir Necesidad, predominio del reino de la Ananke- o Ananké. Reino que, cada vez más, se intensifica y avanza, y que hoy -como lo destaca Nicol- adquiere una significación nueva en la historia. Tan inédita como alarmante. Pues lo que el predominio de la escasez y la necesidad traen consigo es el retroceso del hombre histórico a los imperativos de la especie humana por sobrevivir: a sus necesidades instintivas, biológicas. Un regreso involutivo, diriamos, hacia estadios primitivos de la satisfacción impostergable de las necesidades de la primera naturaleza, ahora socavada en sus propios cimientos. Resuena entonces poderosamente la voz de la especie, misma que corresponde al instinto de sobrevivencia; poderosa voz de los que carecen ya de lo básico para vivir, y de los que carecerán mañana de eso mismo. La sombra que viene del futuro es la de los hambrientos y sedientos potenciales que somos todos. La escasez y la alteración ecológica, el trastorno fatídico de la biosfera amenazan el porvenir de todos.

Pero son justamente estos peligros los que dan lugar al imperativo indefectible de que sea precisamente la razón tecnológica la que los enfrente y eventualmente sobrepase. Y esto significa, a juicio de Nicol, que la razón se ponga al servicio exclusivo de la Necesidad, originando el surgimiento de lo que es una nueva forma de razón destinada 
perentoriamente a satisfacer - valga la redundancia- las necesidades de la Necesidad. La razón tecnológica adquiere entonces el carácter de lo que Nicol conceptúa como Razón de Fuerza Mayor. Ésta es una diferente forma de razón, dedicada únicamente a la utilidad y la eficacia. Razón que no da razón -dice- sino que sólo computa y produce. Razón cada vez más impersonal, más forzosa; tan rudimentaria y perentoria por su sometimiento a la necesidad, como abstracta y sofisticada por su colosal construcción tecno-científica.

La razón de fuerza mayor tiene, así, un significado inverso al de la razón de ciencia y filosofía, o sea a la "razón que se da", consagrada a la búsqueda de la verdad y definida esencialmente por aquello que comúnmente se denomina "libertad de pensamiento".

Y como es fácil inferir, lo amenazado por la fuerza mayor, por el imperio de la Ananke o necesidad, no es sólo la razón simbólica, sino todas las vocaciones libres. Y también significativamente está amenazada la propia tecno-logía, en tanto que obra humana nacida del logos y de la libre inventiva.

Lo que peligra es la libertad misma y con ella lo propiamente humano del hombre. Si llega el fin de la filosofía éste no vendrá sólo para ella -afirma Nicol: también será el fin de las vocaciones libres: de la ciencia como tal, de la poesía, de la mística, e igualmente de la política, la economía, etc. Porque ese fin o final no significa otra cosa para el autor de la Crítica de la razón simbólica que la predominancia absoluta de la fuerza de la Necesidad, imposibilitando el ámbito de la libertad.

El enemigo de la libertad de pensamiento no se identifica porque no es un hombre, ni un grupo de hombres, es un enemigo sin rostro, una fuerza que reduce el ámbito de las vocaciones humanas. Su victoria llegará cuando lo posible ya no sea posible: cuando todo lo que hagan los hombres sea lo necesario.

Todo parece indicar, así, que el temor del fin que asalta a Nicol se explica en gran medida por su manera de comprender el riesgo del colapso ecológico; no solamente como peligro de que se extinga la especie humana, sumándose como una especie más de las que han desaparecido, sino de que no haya lugar ya para la "humanidad" del homo humanus: no haya lugar para "aquello que nos hace ser humanos". La especie biológica podrá sobrevivir porque justamente cuenta con la razón tecnológica de fuerza mayor, destinada a asegurar su sobrevivencia. Lo que no está asegurado en cambio, para Nicol, es la condición propiamente libre, histórica y ética del hombre, el potencial humano de existir en libertad y no sólo subsistir.

Y es inevitable preguntarse si, aún en este escenario sombrío vislumbrado por Nicol, es posible el encuentro de la razón con la esperanza. A lo cual él respondería al menos en dos contextos: reafirmando, por un lado que

[...] la esperanza de seguir siendo lo que es, hasta el fin, no la puede perder [la filosofía] ni en el temor del fin.

Y, por otro lado, declarando significativamente que:

La situación actual puede considerarse todavía problemática mientras quede una esperanza: mientras sea posible siquiera que la ciencia defina con rigor los componentes de esa situación, $y$ que detrás de ella la sapiencia humana conciba y ejecute medidas drásticas para detener el "progreso".

Pero con esto sobrevienen otras interrogantes:

¿En qué se cifra esa sapiencia humana como fundamento último de esperanza? ¿Habría, en él los propios términos de Nicol, indicios de salidas, de caminos por recorrer para conjurar el peligro de la Anánke universal que amarga la vida humana?

La conciencia del problema y "el análisis de los componentes de la situación", señalarían en efecto, cuáles serían las únicas rutas posibles de la sapiencia salvadora:

Desde luego, la primera de ellas, es el camino emprendido por el propio Nicol por cuanto a la recuperación de los significados y valores esenciales de las vocaciones libres, de la philía, y de la razón que da razón. Recuperación que trae consigo el reconocimiento de lo que representa intrínsecamente la conquista simbólica del mundo; esa conquista que es otra forma de poseerlo y transformarlo con sólo nombrarlo, conocerlo, embellecerlo, valorarlo, dotarlo de sentido. 
Se trata, en efecto, del empeño puesto en la reivindicación de esa otra forma de praxis que es la de la vida teorética contemplativa, la de la creación simbólica, espiritual, cultural, distinta de la producción material; distinta incluso de la transformación práctica de la moral, la política, la economía, el derecho. Y esto implica la reafirmación del significado esencial de la acción formativa, humanizadora, de las ciencias puras, la filosofía, las artes, las humanidades. Se trata, en fin, de recobrar el espacio vital y social de las actividades inútiles y revalorar, con ello, la dimensión contemplativa y simbólica de la vida humana.

Sin embargo, es manifiesto que éste será un espacio imposible de recuperar mientras prosiga la hybris tecnológica: hybris, en tanto que desmesura y en tanto que soberbia, ambas. Se desprende de las reflexiones nicolianas que hay al menos estas dos inmediatas exigencias para la demasía tecnológica: frenar su desarrollo y al mismo tiempo revertir, con sus propios poderes, el proceso destructor de la naturaleza y el avance catastrófico de la escasez y la necesidad totales.

Y podría agregarse que estas dos acciones, el freno a la desmesura y la reversión del daño, son manifiestamente irrealizables si no es por medio de una verdadera penetración ética, ético-política en el corazón mismo de los actores del proceso tecnológico; si no es a través de una racionalización humanizada de los fines de la tecnociencia que propicie el libre control de su desarrollo, permitiendo desviar su cauce fatal y destructor, hacia una dirección racional, humanizada y vital.

Pero para alcanzar estos objetivos se requiere un verdadero cambio de actitud en la sociedad; una transformación del ethos colectivo, que permita esa libre racional y consensuada conducción de la techné hacia los bienes éticos y sociales de la vida humana; se necesita, en suma, producir un giro completo en la disposición básica, que haga posible reafirmar a la propia tecnología en su componente de libertad y "sobrenaturaleza", superando con ello su esclavización al poder y al afán de dominio, así como al imperio, presente y futuro, de la uniformidad y la necesidad.

Más allá de la letra de Nicol, pero quizás no de su espíritu, todo indica que la sapiencia salvadora debe abarcar, en efecto, a la propia tecnología. Se requiere ciertamente "una ética para el mundo tecnológico" -como lo formula Hottois- y, más ampliamente comprendido, se requiere, diriamos, "una nueva sapiencia para la tecnociencia".

Con este propósito, es manifiesto que la tecnología tiene que poner su extraordinario potencial (y yo agregaria, su insoslayable maravilla) al servicio, tanto al rescate del Planeta como de la propia creación de las vocaciones libres en toda su gama. Dicho de otro modo: la tecnología ha de seguir persiguiendo la utilidad y ha de cumplir con cabal eficacia su cometido. Pero, al mismo tiempo, la tecnociencia humanizada debe mantenerse fiel al objetivo de la liberación humana de las necesidades, conservando su propia capacidad de libre inventiva.

El reto es, ciertamente, conjurar la sombra que viene del futuro, confiando, con el propio Nicol, en que:

No todo es oscuro en la perspectiva del porvenir. Pero la salvación depende de nosotros.

Es posible, sin embargo, que a pesar de estos destellos de esperanza, prevaleciera en Eduardo Nicol la incertidumbre y el temor por el destino de la humanidad del hombre. Sólo que, indudablemente, éstos contrastarian, en el orden personal, con su certidumbre vocacional, con su inquebrantable confianza y seguridad en el valor de la philía y, con ella, de la libertad del pensamiento.

Es esta suficiencia del libre pensar la que hace que, ya cerca de su muerte y refiriéndose a su experiencia en la Universidad Nacional de México, donde escribió toda su obra filosófica y dedicó casi seis décadas de su vida a la enseñanza, Nicol pudiera comunicar que:

\section{[...] fue una tarea gozosa. Hacer lo que uno quiere. Pensar} y enseñar a pensar ¿Qué más puede pedirse?

Y para terminar, quisiera solamente apuntar que pensar en español fue sin duda la actividad que Eduardo $\mathrm{Ni}$ col ejerció con excepcional ejemplaridad. Su obra escrita, tanto como su enseñanza oral, hacen patente la notable virtud de nuestra lengua de conjugar en armonía las arduas exigencias de la penetración y el rigor filosóficos con la fuerza comunicativa de la palabra bella. No podía ser de otro modo para quien pensamiento y lenguaje son consustanciales. 
Es cierto que, en principio, pensar en español no puede ser para Nicol algo distinto de pensar en cualquier otro idioma. El español tendría inequívocamente las mismas capacidades que otras lenguas para ejercer la ciencia-filosofía (obviamente la filosofía no piensa solamente en griego y en alemán).

La ciencia es igual en todas partes. La ciencia es una lengua universal y no presenta, en tanto que ciencia, diferencias peculiares.

Nicol expresa reiteradamente su convicción de que la filosofía hispánica se ha de constituir también como "ciencia rigurosa" -según la consabida fórmula husserliana. $Y$ esto implica, dejar atrás los prejuicios de que nuestra filosofía sólo se pueda configurar en el orden del ensayo y con validez circunstancial y personalista. Por el contrario, para él, como se ha destacado, la filosofía es ciencia, con todos los atributos de ésta, entre los que sobresalen la objetividad y el dar razón.

Y al mismo tiempo, también congruente con su propia filosofía, el autor de El problema de la filosofía hispánica, se pronuncia en definitiva por la necesidad de conjuntar la universalidad y la identidad cultural de las filosofías, reafirmando así su tesis sustantiva de la unidad indisoluble de la verdad y la historicidad, de la significación y la expresión. La meta sería:

Pensar con auténtica originalidad y hacer filosofía con caracteres a la vez autóctonos y universales.

De este modo, "pensar en español" implica también, para Nicol, pensar desde las propias raíces; armonizar el horizonte universal del pensamiento, con las virtudes de una tradición cultural -la de la hispanidad-destacada por su sapiencia humanista y vitalista. Desde aquí precisamente se haría posible, dice:

un pensar no uniformado, con estilo propio.

Pensar en español conlleva, en fin, para Eduardo Nicol, la vital conjugación de esos dos aspectos de la célebre metáfora de Octavio Paz: "alas y raíces". No es, para Nicol, un pensar sin alas, ni un pensar sin raíces. Raíces que se hunden en la hispanidad, y alas que Ilegan hasta Mileto, Éfeso y Atenas.

Recibido: 8 de octubre de 2007

Aceptado: 21 de diciembre de 2007 